\title{
sciendo
}

\section{Genetic and reproductive toxicity of lamivudine, tenofovir disoproxil fumarate, efavirenz and their combination in the bone marrow and testicular cells of male mice}

\author{
Adekunle A. Bakare ${ }^{1 *}$, Kehinde M. Akinseye ${ }^{1,2}$, Bayonle A. Aminu ${ }^{1,3}$, Francis C. Ofoegbu, \\ Saheed O. Anifowose ${ }^{1,4}$, Stork Abruda ${ }^{1}$, Opeoluwa M. Fadoju' ${ }^{1}$, Olusegun I. Ogunsuyi ${ }^{1,5}$, \\ Ifeoluwa T. Oyeyemi', Okunola A. Alabi ${ }^{7}$, Olusola M. Adetona ${ }^{8}$ and Chibuisi G. Alimba ${ }^{1,9}$
}

\author{
${ }^{1}$ Cell Biology and Genetics Unit, Department of Zoology, University of Ibadan, Ibadan, Nigeria. \\ ${ }^{2}$ Department of Molecular Biosciences, University of Kansas, Lawrence, Kansas, USA. \\ ${ }^{3}$ Department of Environmental Health, College of Medicine, University of Cincinnati, P. O. Box 670056, Cincinnati, OH. USA. \\ ${ }^{4}$ Department of Zoology, King Saud University, Riyadh, Saudi Arabia. \\ ${ }^{5}$ Department of Biological Sciences, Mountain Top University, Ibafo, Ogun state. Nigeria. \\ ${ }^{6}$ Department of Biological Sciences, University of Medical Sciences, Ondo. Nigeria. \\ ${ }^{7}$ Department of Biology, Federal University of Technology, Akure, Nigeria. \\ ${ }^{8}$ Department of Anatomy, College of Medicine, University of Ibadan, Ibadan, Nigeria. \\ ${ }^{9}$ Leibniz Research Centre for Working Environment and Human Factors (IfADo), Technical University of Dortmund, 44139 Dortmund, \\ Germany.
}

Received $4^{\text {th }}$ October, 2019, Accepted 23 ${ }^{\text {rd }}$ December, 2019

DOI: 10.2478/ast-2020-0001

*Corresponding author

Adekunle A.Bakare E-mail: adebakar19@yahoo.com,adekunle.bakare@ui.edu.ng

Tel: +234-7032295419

Abstract

The combination of antiretroviral (ARV) drugs: lamivudine, tenofovir disoproxil fumarate (TDF) and efavirenz is among the preferred first-line regimens for adolescents and adults infected with HIV. However, knowledge on in vivo genetic and reproductive toxicity of each of these drugs and their combination is limited. We evaluated the genotoxicity of lamivudine, TDF, efavirenz and their combination utilizing the mouse micronucleus (MN) and sperm morphology tests. Histopathological analysis of the testes of exposed mice was also carried out. $0.016,0.032,0.064$ and $0.129 \mathrm{mg} / \mathrm{kg}$ bwt of lamivudine, TDF and the combination; and 0.032, $0.064,0.129$ and $0.259 \mathrm{mg} / \mathrm{kg}$ bwt of efavirenz corresponding to $0.125,0.250,0.500$ and $1.000 \mathrm{x}$ the human therapeutic daily dose (HTD) of each of the ARVs and their combinations were administered to mice for 5 consecutive days. Data on MN showed a significant increase (p< 0.05) across the tested doses of TDF, efavirenz and the combination, with the combination inducing lower frequency of MN than TDF and efavirenz. Lamivudine did not evoke significant induction of MN. Significant increase in frequency of abnormal sperm cells were observed in the tested samples, however, the combination induced the highest number of abnormal spermatozoa. The ARVs and their combination induced pathological lesions such as vacuolation and necrosis in mice testes. These findings suggest that the individual ARVs and their combination are potentially capable of activating genetic alterations in the bone marrow and germ cells of male mice thereby raising concern for long term use by HIV patients.

Keywords: HIV; Antiretroviral drugs; DNA damage; micronucleus; sperm morphology 


\subsection{Introduction}

The human immunodeficiency virus (HIV)/acquired immunodeficiency syndrome (AIDS) is a major cause of infectious disease related morbidity and mortality. HIV infection was rated the fifth leading cause of disability adjusted life years (DALY) worldwide for people aged 30 - 44 years in 2010 (Ortblad et al., 2013). Globally, 30.8 to 42.9 million people were reportedly living with HIV in 2016, with over 35 million deaths recorded due to AIDS-related illnesses since the start of the HIV epidemic (UNAIDS, 2017).

At present, no cure exists for HIV infections; however, management of the condition requires continuous daily use of antiretroviral drugs (ARVs) to prevent further weakening of a patient's immune system by inhibiting the HIV replication process. At least thirty-nine single and combinations of ARVs have received approval of the U.S Food and Drug Administration (U.S. FDA) (AIDS, 2017) for the treatment of HIV/AIDS. These FDA-approved ARVs belong to one of five classes of drugs characterised by their molecular mechanism of action and the stage of life-cycle of the virus they inhibit. The ARV classes are: nucleoside/nucleotide reverse transcriptase inhibitors (NRTIs/NtRTIs); protease inhibitors (PIs); integrase inhibitors (INIs); entry inhibitors (EIs); and non-nucleoside reverse transcriptase inhibitors (NNRTIs) (Calmy et al., 2009; Azu, 2012).

Antiretroviral therapy (ART) was originally administered as a monotherapy. This approach was later considered sub-optimal due to the instability of the HIV genome which allowed strains of the virus to undergo several mutations in a relatively short time span, causing them to quickly become resistant to a particular type of ARV (Broder, 2010; Kumari and Singh, 2012). To mitigate this effect, there was introduction of the highly active antiretroviral therapy (HAART), also known as combination ART (cART). The development of HAART regimens coupled with recent advancement on the development of an HIV vaccine or a cure has caused a change in the natural history of HIV infections from a progressive illness with an inevitably fatal outcome into a manageable chronic disease requiring life-long ARV treatment (Palella et al., 1998; Tozzi, 2010; Maartens et al., 2014; Aceti et al., 2015; de Moraes Filho et al., 2017).

The World Health Organisation (WHO) currently recommends a threedrug regimen consisting of two NRTIs/NtRTIs in combination with any of NNRTIs, PIs, EIs or INIs for HIV infections treatment. Combination of tenofovir disoproxil fumarate (TDF), lamivudine and efavirenz is one of the preferred first-line regimens for adolescents and adults (WHO, 2016). Lamivudine, an NRTI, is a prodrug analogue of dideoxycytidine that needs three phosphorylation steps by intracellular kinases to produce its pharmacologically active triphosphate anabolite, lamivudine triphosphate (Anderson and Rower, 2010; Else et al., 2012). TDF is an acyclic nucleoside phosphonate diester analogue of deoxyadenosine $5^{\prime}$-monophosphate that needs stepwise diphosphorylation by intracellular kinases to be converted into its bioactive metabolite, tenofovir ( $\mathrm{Ng}$ et al., 2015). It is the only currently approved NtRTI and has long-term action against Hepatitis B virus and HIV. On the other hand, efavirenz is a first- generation NNRTI that was endorsed by the U.S. FDA for HIV-1 infections treatment in 1998. It is an important component of several first-line HAART combinations for the treatment of HIV patients worldwide (de Moraes Filho et al., 2017).

Despite the clinical benefits of managing HIV infections with ARVs, concerns exist about the potential effect of long-term usage of these chemical agents on the genetic material of patients. These concerns have been further exacerbated by the need to combine ARVs in HAART, as the combination may enhance the individual toxic effects they have on the DNA. Administered as monotherapy or in combination, lamivudine, TDF and efavirenz have been shown in in vitro studies to possess genotoxic, mutagenic, carcinogenic and/or teratogenic abilities (Bayram and Topaktaş, 2008; Fang et al., 2009; Franchi et al., 2009; Guimarães et al., 2013). However, only few studies (Lourenço et al., 2010; de Oliveira et al., 2014; Ng et al., 2015; Vivanti et al., 2015; de Moraes Filho et al., 2016) have evaluated the genotoxic effects of these drugs and their combination using animal bioassays. There is therefore need for more studies using different assays and endpoints to obtain information which can help in making informed decisions on the potential DNA damage by lamivudine, TDF and efavirenz individually and in combination.

In this study we assessed the genotoxicity of lamivudine, TDF and efavirenz individually and compared the results with the genotoxic effects of their combination using the mouse bone marrow micronucleus (MN) and sperm morphology tests. In addition, we carried out testicular histopathological examination of exposed male mice.

\subsection{Materials and Method}

\section{Biological model}

Healthy young male Swiss mice (Mus musculus; 6-7 weeks old for MN assay and 11-13 weeks old for sperm morphology assay) procured from the animal breeding facility of the Department of Zoology, University of Ibadan, Nigeria, were housed in transparent plastic cages lined with wood shavings, and provided with standard food pellet and water ad libitum. They were subjected to the natural day-night cycle, ambient temperature and relative humidity. Animals were handled according to standard guidelines prescribed in the Guidelines for Biomedical Research Involving Animals (CIOMS, 2012). The University of Ibadan Animal Care and Use Research Ethics Committee (UI-ACUREC) (UI-ACUREC/App/2015/031) approved the study.

\section{Test drugs and preparation}

Lamivudine (300 mg) and TDF (300 mg) were obtained from Mylan ${ }^{\circledR}$ and Sunrise ${ }^{\circledR}$ laboratories, India, respectively, while efavirenz (600 $\mathrm{mg}$ ) and the combination of lamivudine, TDF and efavirenz were obtained from Hetero Labs Limited, India. Each ARV and the combination of the three ARVs were separately dissolved in normal saline for 24 hours and used as the stock. Four doses: 0.016, 0.032, 0.064 and $0.129 \mathrm{mg} / \mathrm{kg}$ bwt of lamivudine, TDF and the combination; and $0.032,0.064,0.129$ and $0.259 \mathrm{mg} / \mathrm{kg}$ bwt of efavirenz were prepared from the stock suspensions which correspond to 0.125 , 
$0.250,0.500$ and $1.000 \mathrm{x}$ the human therapeutic daily dose (HTD) of each of the ARVs and their combinations. The HTD of lamivudine (Carpenter et al., 1997) and TDF (Andrea et al., 2011) is 300mg, while for efavirenz is $600 \mathrm{mg}$ (Vernazza et al., 2011). The maximum selected dosage corresponds to the human recommended daily dose, and other lower doses were selected arithmetically as a function of the HTD. This is in order to avoid measurement of acute instead of chronic effect of the test drugs on the DNA. The administration and exposure duration were as according to standard guidelines (Schmid, 1975; Wyrobek et al., 1983; Alabi and Bakare, 2011; Turner et al., 2011).

\section{Micronucleus assay}

Eighteen batches of mice ( 4 mice per batch; $25 \pm 3 \mathrm{~g}$ ) were utilised for the MN assay. Batches 1-4 received 0.016, 0.032, 0.064 and 0.129 $\mathrm{mg} / \mathrm{kg}$ bwt of lamivudine; Batches 5-8 received 0.016, 0.032, 0.064 and $0.129 \mathrm{mg} / \mathrm{kg}$ bwt of TDF; Batches $9-12$ received 0.032, 0.064, 0.129 and $0.259 \mathrm{mg} / \mathrm{kg}$ bwt of efavirenz; Batches 13-16 received $0.016,0.032,0.064$ and $0.129 \mathrm{mg} / \mathrm{kg}$ bwt of the combination of the three ARVs; while Batches 17 and 18 received normal saline and cyclophosphamide (Endoxan ${ }^{\circledR}$, Cadila Healthcare, India; $20 \mathrm{mg} / \mathrm{kg}$ bwt) as negative and positive controls, respectively. Mice were intraperitoneally (IP) administered $0.5 \mathrm{~mL}$ of each ARV drug and their combination for 5 consecutive days while those in the positive control batch were administered a single dose of cyclophosphamide 24 hours prior to sacrifice. The IP route was employed in this study because it allows high bioavailability of substances and circumvents certain unpredictability associated with gastric absorptive processes (Turner et al., 2011). Mice in the test batches were sacrificed 6 hours after the last administration.

The method of Schmid (1975) modified by Alabi and Bakare (2011) was used for the preparation of bone marrow suspension from each mouse. The femurs from each mouse were excised, the proximal epiphyses cut out and $1000 \mu \mathrm{L}$ of Fetal Bovine Serum (FBS; PAA laboratories, GMBH, Paschang, Austria) was used to flush the bone marrow cells from both femurs. The resultant mixture was centrifuged for 5 mins at $2000 \mathrm{rpm}$ and $50 \mu \mathrm{L}$ of FBS was subsequently added to the pellet for slide preparation. Four thousand erythrocytes were scored for MN in polychromatic erythrocytes (MNPCEs) of each mouse at x1000 magnification.

\section{Sperm morphology test}

The method of Wyrobek et al. (1983), with slight modification by Bakare et al. $(2005 ; 2016)$ was used for the sperm morphology test. Five mice (12 - 14 weeks old; $30 \pm 2 \mathrm{~g}$ ) per batch, same number of batches, doses, administered volume, exposure route and exposure duration as in the MN assay, were utilised. The mice were sacrificed on the 35th day from the first day of exposure. This is because of 34.5 days duration of a spermatogenic cycle in mice (Bartke et al., 1974). The cauda epididymes of the mice were surgically excised and sperm suspensions were prepared in a mixture of normal saline and $1 \%$ eosin Y stain. The suspension was left for 45 minutes to allow for proper staining before use in slide preparation. The slides were then allowed to air dry overnight. One thousand sperm cells per mouse were scored according to the criteria of Wyrobek and Bruce (1975) at x1000 magnification.

\section{Histological examination of the testes}

The testes of treated and control mice in the sperm abnormality test were surgically removed and preserved in Bouin's fluid for 48 hours prior to tissue preparation. The preserved testes were thoroughly rinsed using $50 \%$ ethanol to remove the yellow colouration of picric acid. They were then dehydrated in graded alcohol, cleared using two changes of xylene and embedded in paraffin wax, using tissue embedding system (Leica EG 1160). Haematoxylin and eosin were used to stain $4 \mu \mathrm{m}$ thick serial sections of the testes for pathological examination at $\mathrm{x} 400$ magnification.

\section{Analysis of Data}

Data were analysed using GraphPad Prism 5.01 and presented as mean \pm SE. Statistical comparisons were performed using the one-way analysis of variance (ANOVA) followed by Dunnett's post-hoc test at 0.05 level of significance. The combination index (CI) of the three ARV drugs was calculated using the CompuSyn software (CompuSyn, Inc). $\mathrm{A} \mathrm{CI}=1$ depicts additive effect, while $\mathrm{CI}>1$ and $<1$ depicts antagonism and synergism, respectively (Chou, 2010).

\subsection{Results}

\section{Micronucleus assay}

Table 1 presents the mean value of MNPCEs induced in mice treated with different doses of lamivudine, TDF, efavirenz and their combination, as well as the drug CI. Compared with the negative control, TDF and efavirenz individually induced significant increase in MNPCE at the tested doses. The induction of MN by TDF was dosedependent with the highest dose of $0.129 \mathrm{mg} / \mathrm{kg}$ bwt inducing the most frequency of MN $(16.75 \pm 2.46)$. Induction of MN by efavirenz on the other hand was not dose-dependent as the lowest dose $(0.032$ $\mathrm{mg} / \mathrm{kg} \mathrm{bwt})$ induced the highest frequency of MN (12.25 \pm 2.14$)$. At low doses ( 0.032 and $0.064 \mathrm{mg} / \mathrm{kg}$ bwt), efavirenz was more genotoxic than TDF, inducing a higher frequency of MNPCE; however, at high doses ( 0.064 and $0.129 \mathrm{mg} / \mathrm{kg}$ bwt), TDF showed higher genotoxicity than efavirenz. There was no significant increase in MNPCE by lamivudine at the tested doses. The combination of the three ARVs induced significant dose-dependent MNPCE compared to the negative control. At low (0.016 and $0.032 \mathrm{mg} / \mathrm{kg}$ bwt) and high (0.064 and $0.129 \mathrm{mg} / \mathrm{kg} \mathrm{bwt}$ ) doses, the combination was less genotoxic compared to efavirenz and TDF individually. The CI of greater than 1 was obtained at the tested doses for the combination. Figure 1 shows representative images of MNPCE and PCE in the treated mice.

\section{Analysis of sperm abnormalities}

A summary of the frequency of sperm abnormalities induced in mice treated with lamivudine, TDF and efavirenz alone and in combination is presented in Table 2. Lamivudine induced a significant increase in sperm abnormalities only at $0.129 \mathrm{mg} / \mathrm{kg}$ bwt compared to the negative control. Efavirenz and TDF caused a dose-dependent significant increase in abnormal sperm shape, except at $0.016 \mathrm{mg} / \mathrm{kg}$ bwt of TDF. In comparison to TDF, efavirenz induced more sperm abnormalities at the tested doses. The combination of the three ARVs also induced a significant, dose-dependent increase in sperm abnormalities compared to the negative control. However, the induction was highest at all the doses of the combination than with 
lamivudine, TDF and efavirenz individually. Figure 2 presents the observed sperm shape anomalies in mice exposed to lamivudine, TDF, efavirenz and their combination.

\section{Histological examination of mice testicular sections}

Normal tissue cellular architecture was observed in the testes of mice in the negative control group (Figure 3a), but in the groups treated with lamivudine, TDF and efavirenz individually and in combination, there was disruption of the normal testicular cellular architecture.
These disruptions include tubular deformation, increased luminal width, sloughing of the germinal epithelium, shrunken seminiferous tubules, interstitial cell proliferation, seminiferous epithelium vacuolisation and necrosis of the spermatogonia (Figure $3 \mathrm{~b}-\mathrm{d}$ ). The lesions were most severe in the efavirenz-treated mice.

Table 1: The mean $( \pm$ SE) of MNPCEs induced in the bone marrow of mice treated with different doses of lamivudine, tenofovir disoproxil fumarate (TDF) and efavirenz and their combination for 5 days.

\begin{tabular}{lllllll}
\hline $\begin{array}{c}\text { Dose levels } \\
\text { (mg/kg } \\
\text { bwt) }\end{array}$ & Lamivudine & \multicolumn{1}{c}{ TDF } & $\begin{array}{c}\text { Lamivudine }+ \\
\text { TDF }+ \\
\text { Efavirenz }\end{array}$ & $\begin{array}{c}\text { Dose levels } \\
\text { (mg/kg } \\
\text { bwt) }\end{array}$ & Efavirenz & CI \\
\hline NC & $3.75 \pm 0.25$ & $3.75 \pm 0.25$ & $3.75 \pm 0.25$ & NC & $3.75 \pm 0.25$ \\
0.016 & $6.25 \pm 0.75$ & $8.50 \pm 1.71^{*}$ & $8.75 \pm 0.85^{*}$ & 0.032 & $12.25 \pm 2.14^{* *}$ & 1.29 \\
0.032 & $7.50 \pm 0.87$ & $8.00 \pm 0.82^{*}$ & $9.70 \pm 1.11^{* *}$ & 0.064 & $10.75 \pm 1.31^{*}$ & 1.58 \\
0.064 & $6.50 \pm 1.32$ & $13.50 \pm 1.85^{* *}$ & $10.25 \pm 1.38^{* *}$ & 0.129 & $9.75 \pm 2.49^{*}$ & 2.43 \\
0.129 & $6.00 \pm 1.08$ & $16.75 \pm 2.46^{* *}$ & $12.50 \pm 0.65^{* *}$ & 0.259 & $11.00 \pm 0.41^{*}$ & 32.7 \\
PC & $20.25 \pm 2.53^{* *}$ & $20.25 \pm 2.53^{* *}$ & $20.25 \pm 2.53^{* *}$ & PC & $20.25 \pm 2.53^{* *}$ & \\
\hline
\end{tabular}

Data are shown as Mean \pm SE $(n=4){ }^{*} \mathrm{p}<0.05$; $^{* *} \mathrm{p}<0.01$ compared with negative control (NC): normal saline.

Positive control (PC): Cyclophosphamide (20 mg/kg bw).

Table 2: The mean $( \pm$ SE) of abnormal spermatozoa induced in mice intraperitoneally exposed to different doses of lamivudine, tenofovir disoproxil fumarate (TDF), efavirenz and their combination for 35 days.

\begin{tabular}{llllll}
\hline $\begin{array}{l}\text { Dose levels } \\
\text { (mg/kg bwt) }\end{array}$ & Lamivudine & TDF & $\begin{array}{l}\text { Lamivudine }+ \\
\text { TDF + Efavirenz }\end{array}$ & $\begin{array}{l}\text { Dose levels } \\
\text { (mg/kg bwt) }\end{array}$ & Efavirenz \\
\hline $\mathrm{NC}$ & $73.50 \pm 9.04$ & $73.50 \pm 9.04$ & $73.50 \pm 9.04$ & $\mathrm{NC}$ & $73.50 \pm 9.04$ \\
0.016 & $96.20 \pm 18.24$ & $101.20 \pm 6.22$ & $192.40 \pm 5.51^{*}$ & 0.032 & $116.80 \pm 7.00^{*}$ \\
0.032 & $100.40 \pm 8.58$ & $115.60 \pm 18.31^{*}$ & $238.00 \pm 16.45^{* *}$ & 0.064 & $169.20 \pm 7.64^{*}$ \\
0.064 & $107.00 \pm 16.58$ & $125.60 \pm 16.19^{*}$ & $253.00 \pm 3.62^{* *}$ & 0.129 & $175.00 \pm 15.22^{*}$ \\
0.129 & $117.80 \pm 21.91^{*}$ & $168.60 \pm 26.71^{*}$ & $284.60 \pm 19.00^{* *}$ & 0.259 & $189.60 \pm 13.67^{*}$ \\
PC & $244.60 \pm 2.98^{* *}$ & $244.60 \pm 2.98^{* *}$ & $244.60 \pm 2.98^{* *}$ & PC & $244.60 \pm 2.98^{* *}$
\end{tabular}

Data represent Mean \pm SE $(n=5) .{ }^{*} p<0.05 ;{ }^{* *} \mathrm{p}<0.01$ compared with negative control (NC): normal saline.

Positive control (PC): Cyclphosphamide (20 mg/kg bwt).

1000 sperm cells per mouse were assessed. 


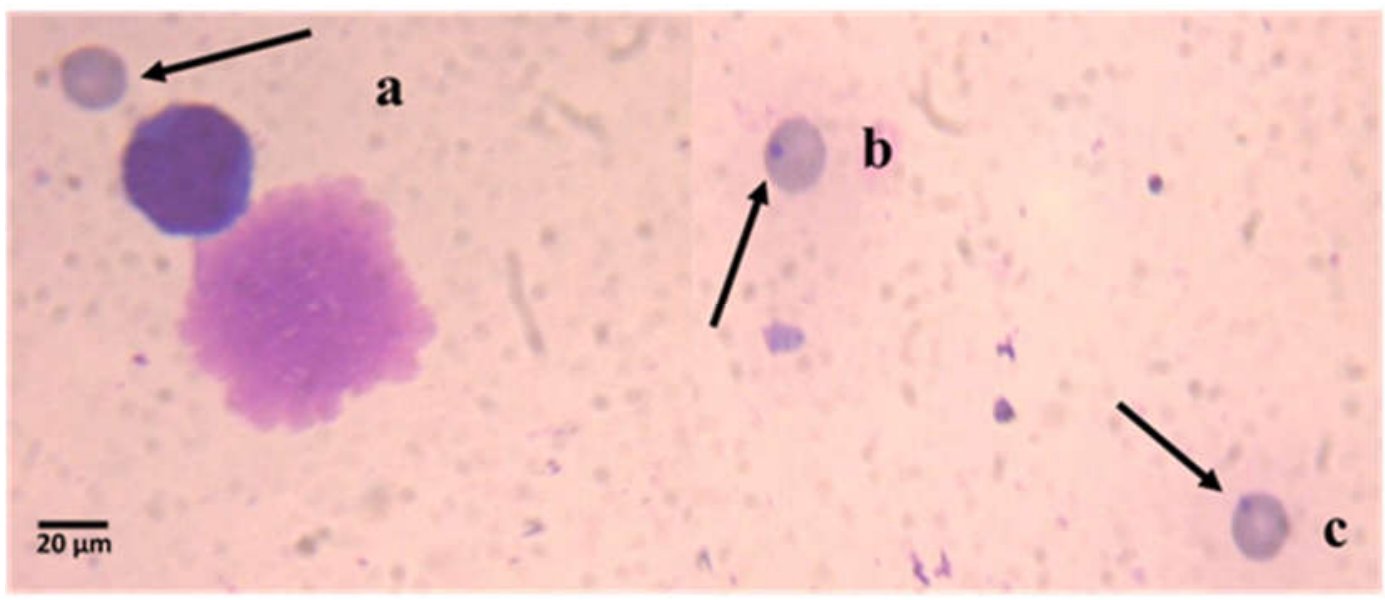

Figure 1: Representative photomicrographs of normal polychromatic erythrocyte (PCE) and micronucleated polychromatic erythrocyte (MNPCE) in the bone marrow of mice intraperitoneally exposed to lamivudine, tenofovir disoproxil fumarate and efavirenz, and their combination. (a) PCE; (b and c) MNPCE. Magnification: x1000)

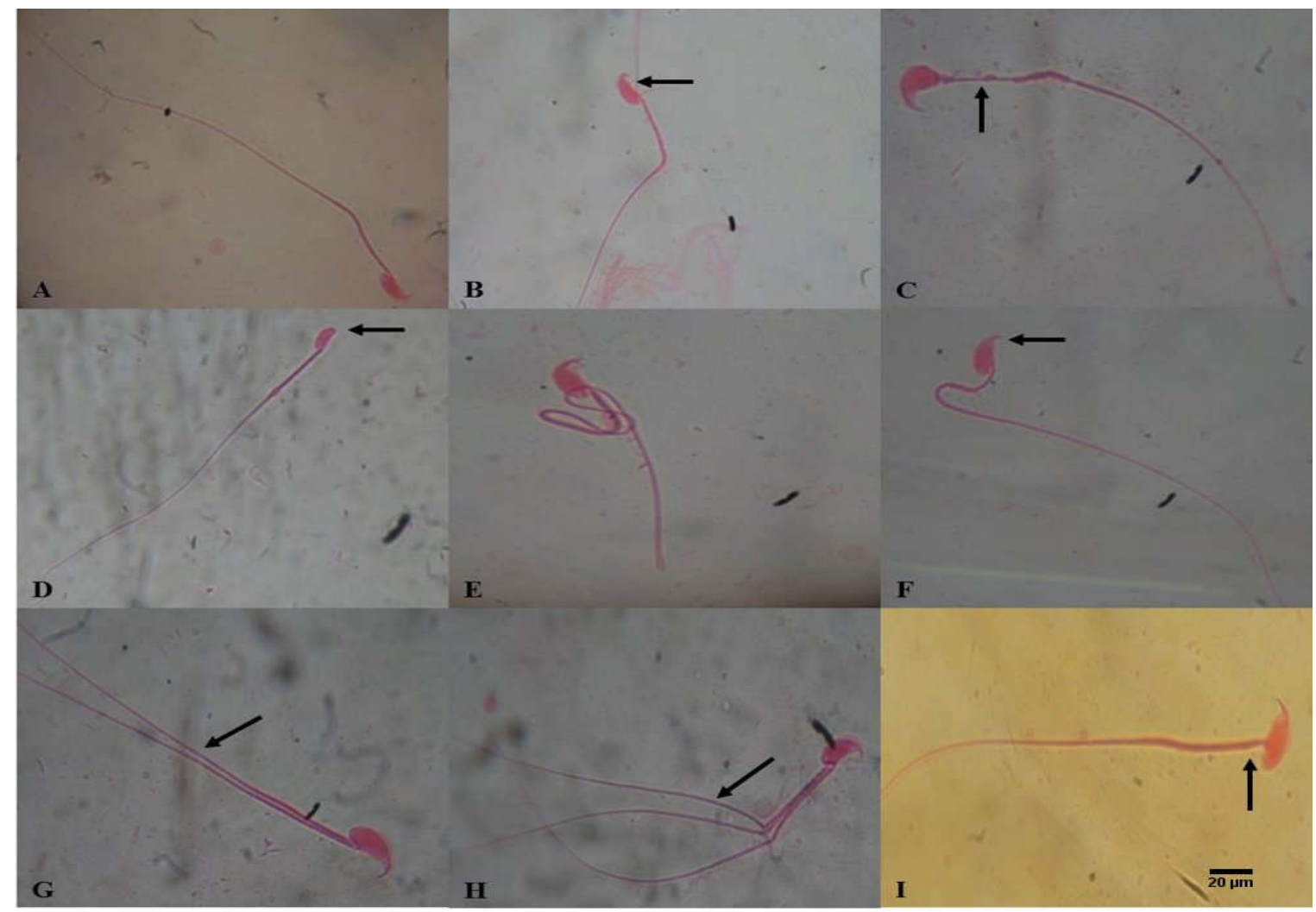

Figure 2: Abnormal sperm cells induced in mice intraperitoneally exposed to different doses of lamivudine, tenofovir disoproxil fumarate and efavirenz individually and their combination. (a) normal sperm cell (b) knobbed hook (c) amorphous head and atrophied midpiece (d) no hook (e) folded sperm (f) short hook (g) sperm with two tails (h) sperm with three tails (i) wrong tail attachment. Magnification: x1000. 

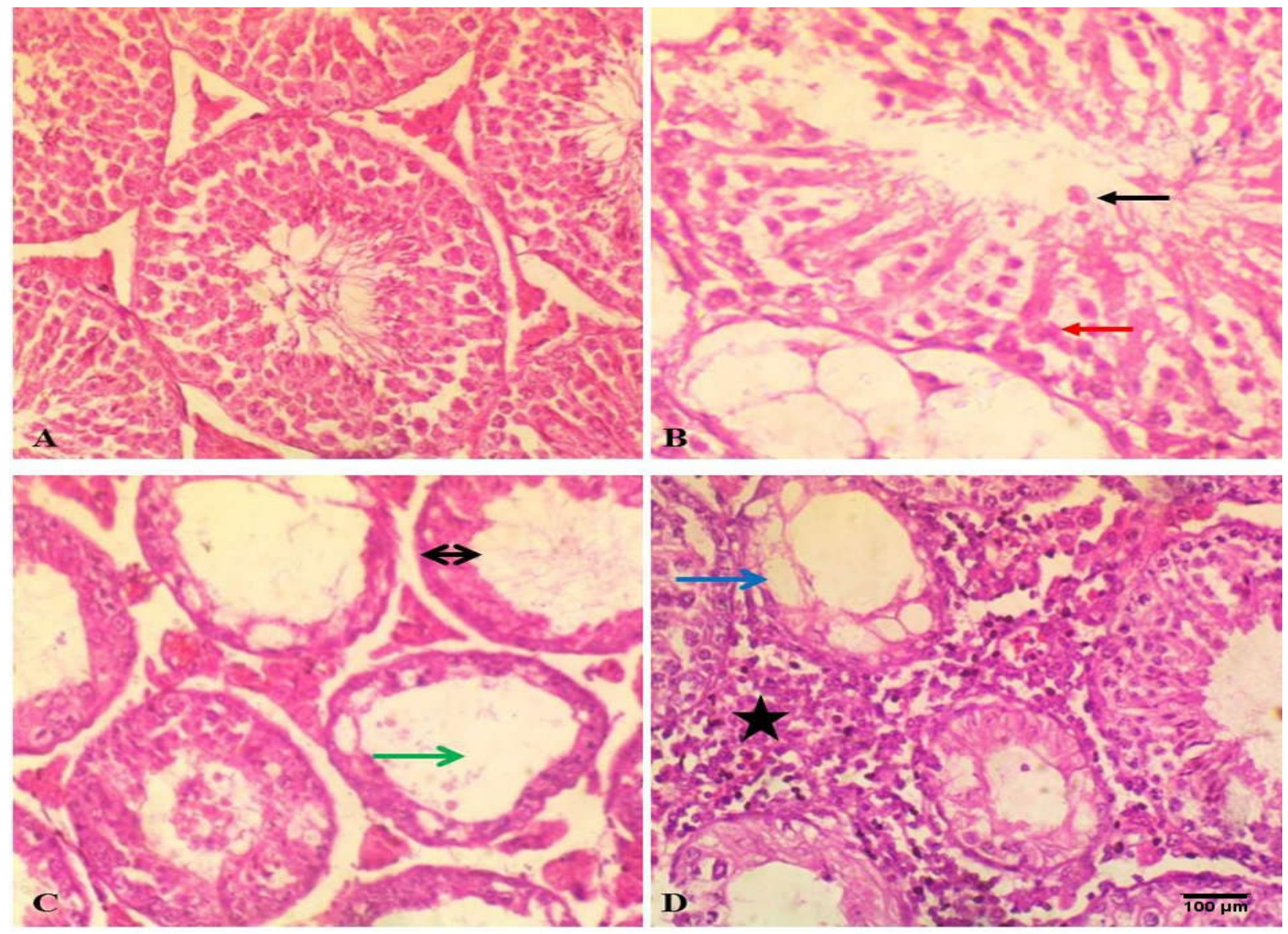

Figure 3: Representative photomicrographs of histoarchitecture of testicular sections of mice in the negative control and those treated with different doses of lamivudine, tenofovir disoproxil fumarate and efavirenz, individually, and their combination. (A) cross-section of normal testicular tissue showing seminiferous tubule with no visible lesions (B) necrosis of spermatogonia (black arrow); apical sloughing of germinal epithelium (red arrow) (C) decrease in diameter of the seminiferous epithelium (double ended arrow) and increase in luminal width (green arrow) (D) seminiferous epithelium vacuolation (blue arrow) and interstitial cell proliferation resulting in congestion of the interstitial space (black star) (Magnification: $\mathrm{x} 400$ ).

\subsection{Discussion}

The use of lamivudine, TDF, efavirenz and their combination for ameliorative treatment of HIV/AIDs is of immense benefit to the patients, as the disease can now be managed and the diagnosis is no longer a death sentence unlike it was considered to be previously. However, since these drugs are administered continuously throughout the life of the patient, there is need to maximize their tolerability and safety. There is a growing concern about the possible toxicity of this class of drugs especially on the DNA both in the short- and long-term use. This study showed that lamivudine, TDF and efavirenz, individually and in combination caused genetic damage in somatic and gonadal cells of mice as assessed by the mouse bone marrow MN and sperm morphology assays.

The in vivo MN assay is widely utilised to evaluate the ability of test agents to induce chromosomal damage and/or mitotic disturbances (Hwang et al., 2013; Oyeyemi et al., 2015). The result of the MN assay showed that TDF, efavirenz and their combination are clastogenic and/or aneugenic at the tested doses. This shows that TDF and efavirenz probably have the ability to alter DNA as suggested by
Vivanti et al. (2015), thereby generating primary and/or secondary DNA damage, resulting in accentric chromosome fragments or chromosome loss. The mechanism(s) by which ARVs exert their genotoxicity are essentially unknown, though a number of different mechanisms have been suggested. One possible mechanism that has been postulated is the disturbance of the intracellular nucleotide pool by NRTIs and NtRTIs, like lamivudine and TDF, which could ultimately result in mutations by increasing the rate of errors in nucleotide incorporation by cellular DNA polymerases (Wutzler and Thust, 2001). Most HAART regimens require the addition into cells of at least two nucleoside analogues which may create genomic instability within the cells thereby contributing to increased risk of nuclear and mitochondrial DNA damage. The genotoxic effect of TDF and efavirenz reported herein is in concert with the observations of Vivanti et al. (2015) and de Moraes Filho et al. (2017).

The combination of the drugs showed induction of MN lowered than what was observed with efavirenz and TDF individually. This suggests that interactions of these drugs probably reduce their genotoxic effect in the bone marrow cells of exposed mice. This suggestion was further 
buttressed by the $\mathrm{CI}$ which showed values greater than one, indicating antagonistic effect for the induction of $\mathrm{MN}$ relative to the individual ARVs at the tested doses. This antagonism could be the consequence of a non-competitive inhibition between the two NRTI/NtRTIs and the NNRTI drugs. Antagonistic genotoxic effect of lamivudine, TDF and efavirenz have also been reported by de Moraes Filho et al. (2017) in a study that utilised the somatic mutation and recombination test (SMART) and comet assay.

Data of the MN test further showed that lamivudine alone was not genotoxic at the tested doses. This is an indication that lamivudine is probably not a clastogenic or aneugenic agent. Weak/no induction of genotoxicity by Lamivudine was reported by de Moraes Filho et al. (2016) and Fang et al. (2009) in mice bone marrow and in NIH 3T3 cells, respectively. Perhaps, this is why lamivudine is categorised as weak inducer of MN formation and gross mutation (Bayram and Topaktas, 2008).

Result of the sperm shape test revealed that lamivudine, TDF, efavirenz and their combination are capable of altering the process of spermatogenesis and damaging mouse germ cells. The murine sperm shape test is among the most widely utilized genetic toxicology assays (Rasgele, 2014). It is a sensitive and reliable endpoint for evaluating and identifying xenobiotics capable of increasing spermatogenic dysfunction (Wyrobek and Bruce, 1975) and has been successfully employed in biological monitoring, environmental pollution assessment and in drug toxicity (Utulu and Bakare, 2010; Alabi et al., 2019). In our study, lamivudine induced abnormal sperm cells only at the highest dose of $0.129 \mathrm{mg} / \mathrm{kg}$ bwt, indicating weak genotoxic effect on the sperm cells similar to its observed effect in the bone marrow cells. High frequency of abnormal sperm cells induced by TDF and efavirenz herein showed that both drugs can induce DNA damage during sperm cell formation. Induction of abnormal sperms is assumed to result from point mutation (Bruce and Heddle, 1979), chromosomal aberration (Bruce et al., 1974) and small deletions in testicular DNA (Giri et al., 2002). This is therefore an indication of the ability of TDF and efavirenz to induce sperm cell abnormalities in other animals, including humans, by inducing chromosomal aberrations or gene mutation during the packaging of DNA in the sperm head (Bruce et al., 1974; Bruce and Heddle, 1979).

The combination of the ARVs provoked more abnormal sperm cell formation than the individual ARV. This is an indication that exposure of cells to two or more types of ARV may cause disruption in the natural deoxynucleotide pool, while such imbalances may lead to the triggering of genomic instability thus increasing the risk of repairable or permanent injuries for the nuclear and mitochondrial DNA (Morris et al., 2009; Guimaraes et al., 2013). The genotoxicity of lamivudine, TDF, efavirenz and their combination using sperm morphology assay suggests potential induction of infertility in male animals. There is a strong association between sperm abnormalities, male infertility and sterility in most species and the sperm structure plays a crucial role in both fertilization and pregnancy outcome (Kumar and Singh, 2015). Aside infertility, this result raises concern about the possibility of these ARVs and their combination to elicit genetic damage which might be transmissible from one generation to another generation. This is because spermatozoa with damaged DNA may introduce damaged genome into the oocytes causing deleterious effects on fertilization, embryonic, foetal and post-natal development (Lewis and Aitken, 2005; Zini, 2011). This therefore calls for more study and special attention to patients of reproductive age using these drugs and their combination to forestall potential side effects in long term use.

To further understand the ability of lamivudine, TDF, efavirenz and their combination to induce testicular toxicity, histopathological examination of the testes of exposed mice was carried out. Histopathological alterations are widely used as biomarkers for chemical and other xenobiotic induced toxicity (Rashid et al., 2012) and are acknowledged as the most sensitive means to detect effects on spermatogenesis (Creasy, 2002; Vidal and Whitney, 2014). The individual ARVs and their combination induced various pathological lesions in the testes of exposed mice including tubular deformation, increased luminal width, sloughing of the germinal epithelium, interstitial cell proliferation, seminiferous epithelium vacuolisation and necrosis of spermatogonia. Induction of histological damage in the testes of exposed mice indicates that ARVs are capable of passing through the blood-testis barrier; thus, providing direct evidence to support the conclusion that ARVs disrupted spermatogenesis in mice, causing elevated frequency of abnormal sperm cells when compared with the negative control.

In conclusion, our study showed that while lamivudine is a weak genotoxic agent, TDF, efavirenz and the combination of the three ARVs demonstrated significant potentials to cause germ and somatic cell genetic damage in male mice. Since genetic damage to cells has been implicated in the aetiology of cancers and congenital abnormalities, it is important that constant monitoring and intervention strategies are established to ensure that patients receiving treatment with these drugs continue to enjoy the quality of life that HIV treatment is supposed to bestow. More studies are required to shed light on the mechanism through which these ARVs induce genetic and testicular toxicity in vivo.

\section{Acknowledgement}

The authors are grateful to authorities of Osogbo state specialist hospital, Asubiaro, Osun State, and the President's Emergency Plan for Aids Relief (PEPFER) at University College Hospital, Ibadan Oyo State for providing some of the drugs used in this study.

\section{Declaration of Conflict of Interests}

The authors declare no conflict of interests.

\section{Funding}

This study was partly supported by the postgraduate vote of Department of Zoology, University of Ibadan

\section{Authors' Contributions}

Conception: $[\mathrm{AAB}]$

Design: [AAB, CGA, OAA, ITO and OMA]

Execution: [KMA, BAA, FCO, SOA, SA, OMF, and OIO]

Interpretation: [OMF, $\mathrm{OIO}$ and ITO] 
Writing the paper: [AAB, CGA, OAA, ITO, OMA, KMA, BAA, FCO, SOA, SA, OMF and OIO]

\section{References}

Aceti, A., Gianserra, L., Lambiase, L., Pennica, A., and Teti, E. (2015). Pharmacogenetics as a tool to tailor antiretroviral therapy: a review, World Journal of Virology, 4(3); 198-208.

AIDS info. FDA-approved HIV medicines. Retrieved March 21, 2017, from https://aidsinfo.nih.gov/education-materials/fact-sheets/21 /58/fda-approved-hiv-medicines.

Alabi, O. A., and Bakare, A. A. (2011). Genotoxicity and mutagenicity of electronic waste leachates using animal bioassays, Toxicological and Environmental Chemistry, 93(5); 1073-1088.

Alabi, O. A., Silva, A. H., Purnhagen, L. R. P., Gabriela, G. R. A., Leonidas, L. J. M., Fabiola, F. B., Dalmina, M., Pittella, F., Bakare, A. A., and Creczynski-Pasa, T. B. (2019). Genetic, reproductive and oxidative damage in mice triggered by co-exposure of nanoparticles: From a hypothetical scenario to a real concern, Science of The Total Environment, 660; $1264-1273$.

Anderson, P. L., and Rower, J. E. (2010). Zidovudine and lamivudine for HIV infection, Clinical Medicine Reviews in Therapeutics, 2; a2004a2023.

Andrea, S., Isaacson, I., McGowan, A., Cheng, R., Schooley, T., and Miller, M.D. (2011). Genotypic and phenotypic analyses of HIV-1 in antiretroviral-experienced patients treated with tenofovir DF, AIDS, 16; $1227-123$

Azu, O. O. (2012). Highly active antiretroviral therapy (HAART) and testicular morphology: current status and a case for a stereologic approach, Journal of Andrology, 33(6); 1130-1142.

Bakare, A. A., Mosuro, A. A., and Osibanjo, 0. (2005). An in vivo evaluation of induction of abnormal sperm morphology in mice by landfill leachates, Mutation Research, 582(1-2); 28-34.

Bakare, A. A., Udoakang, A. J., Anifowoshe, A. T., Fadoju, O. M., Ogunsuyi, O. I., Alabi, O. A., Alimba, C. G., and Oyeyemi, I. T. (2016). Genotoxicity of titanium dioxide nanoparticles using the mouse bone marrow micronucleus and sperm morphology assays, Journal of Pollution Effect and Control, 4; 156.

Bartke, A. J., Weir, A., Mathison, P., Roberson, C., and Dalterio, S. (1974). Testicular function in mouse strains with different age of sexual maturation, Journal of Heredity, 65; 204-208.

Bayram, S., and Topaktaș, M. (2008). Confirmation of the chromosome damaging effects of lamivudine in in vitro human peripheral blood lymphocytes, Environmental and Molecular Mutagenesis, 49; 328333.

Broder, S. (2010). The development of antiretroviral therapy and its impact on the HIV-1/AIDS pandemic, Antiviral Research, 85; 1-18.

Bruce, W., and Heddle, J. (1979). The mutagenicity of 61 agents as determined by the micronucleus, Salmonella and sperm abnormality assays, Canadian Journal of Cytology and Genetics, 21; 319-334.
Bruce, W. R., Furrer, R., and Wyrobek, A. J. (1974). Abnormalities in the shape of murine sperm after acute testicular $\mathrm{x}$-irradiation, Mutation Research, 23; 381-386.

Calmy, A., Hirschel, B., Cooper, D. A. and Carr, A. (2009). A new era of antiretroviral drug toxicity, Antiviral Therapy, 14; 165-179.

Carpenter, C., Fischi, M., and Hammer, S. (1997). Antiretroviral therapy for HIV infection: updated recommendations of the international AIDS society-USA panel, JAMA, 227(24); 1962-1969.

Chou, T. C. (2010). Drug combination studies and their synergy quantification using the Chou-Talalay method, Cancer Research, 70(2); 440-446.

Council for International Organization of Medical Sciences (CIOMS). (2012). International guiding principles for biomedical research involving animals. pp1-4.

Creasy, D. M. (2002). Histopathology of the male reproductive system II: Interpretation, Current Protocols in Toxicology, 16; 4.

de Moraes Filho, A. V., Carvalho, C. J. S., Carneiro, C. C., Vale, C. Rd., Lima, D. C. S., Carvalho, W. F., Viera, T. B., Silva, D. M., Cunha, K. S., and ChenChen, L. (2016). Genotoxic and Cytotoxic Effects of antiretroviral combinations in mice bone marrow, PLoS ONE, 11(11): e0165706.

de Moraes Filho, A. V., Carvalho, C. J. S., Verçosa, C. J., Gonçalves, M. W., Rohde, C., Silva, D. Me.,Cunha, K. S., and Chen-Chen, L. (2017). In vivo genotoxicity evaluation of efavirenz (EFV) and tenofovir disoproxil fumarate (TDF) alone and in their clinical combinations in Drosophila melanogaster, Mutation Research in Genetic Toxicology and Environmental Mutagenesis, 820; 31-38.

de Oliveira, H. M., Damiani, A. P., Dias, R.D.O., Romão, P. R. T., and Andrade, V. M. (2014). Effect of antiretroviral drugs on DNA damage in mice, Environmental Toxicology and Pharmacology, 37; 390-395.

Dobrzynska, M., Gajowik, A., Radzikowska, J., Lankoff, A., and Dusinska, M. (2014). Genotoxicity of silver and titanium dioxide nanoparticles in bone marrow cells of rats in vivo, Toxicology, 315; 86-91.

Else, L. J., Jackson, A., Pils, R., Hill, A., Fahey, P., Lin, E., Amara, A., Siccardi, M., Watson, V., Tjia, J., Emery, S., Khoo, S., Back, D. J., and Boffito, M. (2012). Pharmacokinetics of lamivudine and lamivudinetriphosphate after administration of 300 milligrams and 150 milligrams once daily to healthy volunteers: results of the ENCORE 2 study, Antimicrobial Agents and Chemotherapy, 56(3); 1427-1433.

Fang, J. L., McGarrity, L. J., and Beland, F. A. (2009). Interference of cell cycle progression by zidovudine and lamivudine in NIH 3T3 cells, Mutagenesis, 24(2); 133-141.

Franchi, L. P., Pentiado, N. H. G. R., Silva, R. N., Guimarães, N. N., Jesuino, R. S. A., de Andrade, H. H. R., Lehman, M., and Cunha, K. S. (2009). Mutagenic and recombinagenic effects of lamivudine and stavudine antiretrovirals in somatic cells of Drosophila melanogaster, Food and Chemical Toxicology, 47; 578-582.

Giri, S., Prasad, S.B., Giri, A., and Sharma, G.D. (2002). Genotoxic effects of malathion: an organophosphorus insecticide, using three mammalian bioassays in vivo, Mutation Research, 514; 223-231. 
Guimarães, N. N., Silva, C. J., de Andrade, H. H. R., Dihl, R. R., Lehmann, M., and Cunha, K. S. (2013). Comparative analysis of genetic toxicity of antiretroviral combinations in somatic cells of Drosophila melanogaster, Food and Chemical Toxicology, 53; 299-309.

Guimarães, N. N., Silva, C. J., Andrade, H. H. R., Dihl, R. R., Lehmann, M., and Cunha, K. S. (2013). Comparative analysis of genetic toxicity of antiretroviral combinations in somatic cells of Drosophila melanogaster, Food and Chemical Toxicology, 53; 299-309. doi: 10.1016/j.fct.2012.12.005.

Hwang, Y. H., Park, H., and Ma, J. Y. (2013). In vitro and in vivo safety evaluation of Acer tegmentosum, Journal of Ethnopharmacology, 148(1); 99-105.

Kumar, N., and Singh, A. K. (2015). Trends of male factor infertility, an important cause of infertility: A review of literature. Journal of Human Reproductive Sciences, 8(4); 191-196.

Kumari, G., and Singh, R. K. (2012). Highly active antiretroviral therapy for treatment of HIV/AIDS patients: current status and future prospects and the Indian scenario, HIV \& AIDS Review, 11; 5-14.

Lewis, S. E., and Aitken, R. J. (2005). DNA damage to spermatozoa has impacts on fertilization and pregnancy, Cell and Tissue Research, 322; 33-41.

Lourenço, E. D., do Amaral, V. S., Lehmann, M., Dihl, R. R., Schmitt, V. M., Cunha, K. S., Reguly, M. L., and de Andrade, H. H. R. (2010). Micronuclei induced by reverse transcriptase inhibitors in mononucleated and binucleated cells as assessed by the cytokinesis-block micronucleus assay, Genetics and Molecular Biology, 33(4); 756-760.

Maartens, G., Celum, C., and Lewin, S. R. (2014). HIV infection: epidemiology, pathogenesis, treatment, and prevention, The Lancet, 384(9939); 258-271.

Magdolenova, Z., Collins, A., Kumar, A., Dhawan, A., and Stone, V. (2014). Mechanisms of genotoxicity. A review of in vitro and in vivo studies with engineered nanoparticles, Nanotoxicology, 8; 233-278.

Morris, G. W., Iams, T. A., Slepchenko, K. G., and McKee, E. E. (2009). Origin of pyrimidine deoxynucleotide pools in perfused rat heart: implications for 30-azido-30-deoxythymidine-dependent cardiotoxicity, Biochemistry Journal, 422; 513-520.

Muller, J., Decordier, I., Hoet, P., Lombaert, N., and Thomassen, L. (2008). Clastogenic and aneugenic effects of multi-wall carbon nanotubes in epithelial cells, Carcinogenesis, 29; 427-433.

Ng, H. H., Stock, H., Rausch, L., Bunin, D., Wang, A., Brill, S., Gow, J., and Mirsalis, J. C. (2015). Tenofovir disoproxil fumarate: toxicity, toxicokinetics, and toxicogenomics analysis after 13 weeks of oral administration in mice, International Journal of Toxicology, 34(1); 410.

Ortblad, K. F., Lozano, R., and Murray, C. J. (2013). The burden of HIV: insights from the global burden of disease study 2010, AIDS, 27(13); 2003-2017.

Oyeyemi, I. T., Yekeen, O. M., Odusina, P. O., Ologun, T. M., Ogbaide, O. M., Olaleye, O. I., and Bakare, A. A. (2015). Genotoxicity and antigenotoxicity study of aqueous and hydro-methanol extracts of
Spondias mombin L., Nymphaea lotus L. and Luffa cylindrical L. using animal bioassays, Interdisciplinary Toxicology, 8(4); 184-192.

Palella, F. J., Delaney, K. M., Moorman, A. C., Loveless, M. O., Fuhrer, J., Satten, G. A., Aschman, D. J., and Holmberg S. D. (1998). Declining morbidity and mortality among patients with advanced human immunodeficiency virus infection. HIV Outpatient Study Investigators, New England Journal of Medicine, 338(13); 853-860.

Rasgele, P. G. (2014). Abnormal sperm morphology in mouse germ cells after short-term exposures to acetamiprid, probineb, and their mixture, Archives of Industrial Hygiene and toxicology, 65; 47-56.

Rashid, A., Asmatullah, A., Zara, N., and Ara, C. (2012). Testicular toxicity induced by deltamethrin in albino mice, Pakistan Journal of Zoology, 44 (5); 1349-1353.

Schmid, W. (1975). The Micronucleus test, Mutation Research, 31; 915.

The Joint United Nations Programme on HIV/AIDS (UNAIDS). (2017). Fact sheet July 2017. Retrieved January 20, 2018 from http://www.unaids.org/en/resources/fact-sheet.

Tozzi, V. (2010). Pharmacogenetics of antiretrovirals, Antiviral Research, 85; 190-200.

Turner, P. V., Brabb, T., Pekow, C., and Vasbinder, C. A. (2011). Administration of substances to laboratory animals. Routes of administration and factors to consider, Journal of the American Association for Laboratory Animal Science, 50(5); 600-613.

Utulu, S., and Bakare, A. A. (2010). DNA damage induced in the germ and bone marrow cells of mice by caffeine, West Africa Journal of Pharmacology and Drug Research, 5(8); 536 - 541.

Vernazza, P., Wang, C., Pozniak, A., Weil, E., Pulik, P., and Cooper, D. (2011). Efficacy and safety of lersivirine (UK-453,061) vs. efavirenz in antiretroviral treatment-naive HIV-1-infected patients: week 48 primary analysis results from an ongoing, multicentre, randomised, double-blind, phase IIb trial (study A5271015). 6th IAS Conference on HIV Pathogenesis, Treatment and Prevention; 2011 Jul 1720; Rome, Italy. Abstract TUAB0101.

Vidal, J. D., and Whitney, K. M. (2014). Morphologic manifestations of testicular and epididymal toxicity, Spermatogenesis, 2014 May-Aug; 4(2); e979099 (doi: 10.4161/21565562.2014.979099).

Vivanti, A., Soheili, T. S., Cuccuini, W., Luce, S., Mandelbrot, L., Lechendec, J., Cordier, A. G., Azria, E., Soulier, J., Cavazzana, M., Blanche, S., and André-Schmutz, I. (2015). Comparing genotoxic signatures in cord blood cells from neonates exposed in utero to zidovudine or tenofovir, AIDS, 29; 1319-1324.

World Health Organisation (WHO). (2016). Consolidated guidelines on the use of antiretroviral drugs for treating and preventing HIV infection.

Wutzler, P., and Thust, R. (2001). Genetic risks of antiviral nucleoside analogues - a survey, Antiviral Research, 49; 55-74.

Wyrobek, A. J., and Bruce W. R. (1975). Chemical induction of sperm abnormalities in mice, proceeding of the National Academy of Science, 72; 4425-4429. 
Wyrobek, A. J., Gordon, L. A., Burkhart, J. G., Francis, M. W., Kapp (Jr.), R. W., Letz, G., Malling, H. G., Topham, J. C., and Whorton, M. D. (1983). An evaluation of the mouse sperm morphology test and other sperm tests in non-human mammals. A report of the United States Environmental Protection Agency Gene - Tox Programme, Mutation Research, 115; 1-72.

Zini, A. (2011). Are sperm chromatin and DNA defects relevant in the clinic? System Biology and Reproductive Medicine, 57; 78-85. 